ScIDice

\section{Assessment of Partial Edentulism of Kennedy's Class IV And Its Association to Age and Arch - A Retrospective Analysis}

Research Article

Mohamad Qulam Zaki Bin Mohamad Rasidi ${ }^{1}$, Kiran Kumar Pandurangan², Dinesh Prabu ${ }^{3}$

${ }^{1}$ Saveetha Dental College and Hospitals, Saveetha Institute of Medical and Technical Sciences Saveetha University, Chennai-600077, Tamilnadu, India.

${ }^{2}$ Senior Lecturer, Department of Prosthodontics, Saveetha Dental College And Hospitals, Saveetha Institute Of Medical And Technical Sciences,

Saveetha University, Chennai-600077, Tamilnadu, India.

${ }^{3}$ Senior Lecturer, Department of Oral Maxilofacial Surgery, Saveetha Dental College and Hospitals, Saveetha Institute of Medical and Technical Sciences Saveetha University, Chennai-600077, Tamilnadu, India.

\title{
Abstract
}

Several Decades, various causes for tooth loss to occur in the oral cavity, such as incidence of dental caries, periodontal disease, dental trauma, pulp, and periradicular diseases and also various systemic diseases. There are various classifications to classify partially edentulous arches used by prosthodontists to communicate with each other. The common classification are Kennedy, Applegates, Avant, Skinner, Wild, Bailyn, Cummer, Neurohr. Each classification has its own advantages and disadvantages. Currently, most of the practitioners use Kennedy's classification worldwide due to its immediate visualization and ease thepartial edentulous space differentiation. Therefore, this purpose of this study is to evaluate the partial edentulism of Kennedy's Class IV based on different age groups and arch. An institution-based retrospective study was conducted among partial edentulism patients who visited Private Dental Hospital, Chennai. Data collection was obtained by reviewing 86,000 patients' records between June 2019 and March 2020 of which 96 patients among age groups and arch by doing the clinical examination for evaluating the partial edentulism of Kennedy's Class IV. The data were collected and tabulated in excel sheets which were imported to SPSS version 20. Descriptive statistics and Chi-square tests were used to determine the association between the variables. In this present study, out of 96 patients, partial edentulism of Kennedy's Class IV is more common in the age above 60 years old (24\%) and the most common arch was found to be mandibular arch (57.3\%). This study result concludes that there is a significant association between the age groups and arches for patients with Kennedy's Class IV partial edentulism $(p<0.05)$.

Keywords: Age; Partialedentulous; Prevalence; Visualization.

\section{Introduction}

Edentulism indicates the absence of one or more teeth but not all-natural teeth [1]. It occurs due to dental caries, periodontal diseases, traumatic injuries, teeth impaction, supernumerary teeth, neoplastic and cystic lesions [2]. Dental caries and periodontal diseases are the most common causes of tooth loss $[3,4]$.

In addition, loss of one or more teeth disrupts the functional balance of the remaining teeth which may result in teeth migration, increasing in proximal contact and impaction of food, resorption of bone, occlusal intervention, vertical dimension loss, mastication, anterior overloading, dysfunction of temporomandibular with para-functional activities, phonetics, aesthetics and psychological issues such as self-esteem and confidence [5, 6]. Tooth loss prevention is by limitation of oral disease occurring in oral cavities. Periodontitis and gum diseases may lead to the supporting structure, detachment of the teeth [7-9].

The variation of location and number of the edentulous space occurred and their relation with the remaining teeth structure made the classification of edentulous teeth [10]. The primary aim for the partial edentulism classification is to identify the potential combinations of teeth in ridges, facilitate communication between dental professionals and colleagues, students, and dental technicians [11]. Monitoring the occurrence of partial edentulism

*Corresponding Author:

Kiran Kumar Pandurangan,

Senior Lecturer, Department of Prosthodontics, Saveetha Dental College and Hospitals, Saveetha Institute of Medical and Technical Sciences, Saveetha University,

Chennai 77, India.

Tel: 91-7010782807

E-mail: kirankumar.sdc@saveetha.com

Received: October 28, 2019

Accepted: November 24, 2019

Published: November 28, 2019

Citation: Mohamad Qulam Zaki Bin Mohamad Rasidi, Kiran Kumar Pandurangan, Dinesh Prabu. Assessment of Partial Edentulism of Kennedy's Class IV And Its Association to Age and Arch - A Retrospective Analysis. Int J Dentistry Oral Sci. 2019;S5:02:003:11-14. doi: http://dx.doi.org/10.19070/2377-8075-SI02-05003

Copyright: Kiran Kumar Pandurangan 2019. This is an open-access article distributed under the terms of the Creative Commons Attribution License, which permits unrestricted use, distribution and reproduction in any medium, provided the original author and source are credited. 
is important because it is an indicator of both the health of the population and the adequacy of the national oral health care system $[12,13]$. The lack of organized diagnostic criteria for partial edentulism has been a long-standing obstacle [14].

There are various classifications to classify partially edentulous arches used by prosthodontists to communicate between techniciansand students [15]. The common classification are Kennedy's, Applegates, Avant, Skinner, Wild, Bailyn, Cummer, Neurohr. Each classification has their own advantages and disadvantages. Currently, most of the practitioners use Kennedy's classification worldwide due to its immediate visualization and ease in differentiation $[14,16]$. Several studies conducted on Kennedy's classification amongpatients' treatments highly depends on their socioeconomic status such as monthly income and educational level [17].

Literature review revealing the posterior tooth has more tendencies towards tooth loss and the first permanent molar was found as being the most frequently missing tooth [18-20]. It is due to its early eruption and is mainly absent in the mandibular arch as compared to the maxillary arch where females seem to lose their teeth [21]. Information on dental mortality is relevant in different areas around the world for assessing the adequacy of dental care services and improving the oral health status [22, 23]. In many countries, the pattern of tooth loss has been determined by different populations. Hence, this purpose of this study was to evaluate the prevalence of partial edentulism patients of Kennedy's Class IV classification based on age and arch.

\section{Materials and Methods}

\section{Study Setting}

A retrospective study was conducted among partially edentulous patients with Kennedy's Class IV who visited Private Dental Hospital, Chennai. Ethical approval for the study was granted by the Institutional Ethical Committee, IEC approval number: SDC/ SIHEC/2020/DIASDATA/0618-0319.

\section{Study Subjects}

A total of 96 subjects participated in this study, of which 38 were females and 58 were males.

\section{Methodology}

The data were reviewed of 86,000 patient records between 1 st June 2018 to 31st March 2019 based on data availability from Dental Information Archiving Software (DIAS). Informed consent was obtained from the patients. Clinical examinations were analyzed thoroughly and cross verified with intraoral photographs by another examiner. The subjects were divided into five groups based on age, Group I - 18-30 years; Group II - 31-40 years, Group III - 41-50years. Group IV - 51-60 years, Group V - above 60 years.

\section{Inclusion criteria}

Both male and female patients aged between 18 years and 80 of age and patients who are partially edentulous with Kennedy's
Class IV (A single, but bilateral (crossing the midline), edentulous area located anterior to the remaining natural teeth).

Exclusion criteria: Patients with complete edentulism, missing third molars and Incomplete data were excluded from this study.

\section{Statistical Analysis}

The data were recorded and tabulated in excel sheets which were imported into SPSS Statistics software for Windows, Version 20.0. Chicago (IBM corporation) for statistical analysis. Descriptive statistics and Chi-square tests were used to determine the correlation between the variables, where $\mathrm{p}$-value $<0.05$ is considered statistically significant with a confidence interval of $95 \%$.

\section{Results And Discussion}

Previously our team has conducted numerous original studies [2438] over the past 5 years. The plan for this study stemmed from the current interest in our community. Based on the present study, out of 96 patients of partial edentulism of Kennedy's Class IV were examined, it was found that partial edentulism of Kennedy's Class IV is more common in the age above 60 years old $(24 \%)$ (Figure 1). The results of this present study, similar to the previous studies of $\mathrm{Al}$ Moaleem et al., in which the age groups above 60 years old are most common (30.6\%)[39]. In contrast, withthe previous study done by R.A. Devishree et al.,where Kennedy's Class IV partial edentulous were more common in age groups between 30 to 40 years old [40].

In the present study, partial edentulism was more common in the mandibular arch $(57.3 \%)$ than the maxillary arch (42.7\%) (Figure 2). Similar studies were conducted by Manal et al., where the most common arch was mandibular arch $(60.0 \%)$ when compared to maxillary arch [41]. The disparity with previous studies of Salleh $\mathrm{MM}$ et al., where the most affected arch was a higher prevalence in maxillary arch (66.6\%) than mandibular arch (33.4\%) [42]. The results of this present study showed that there is a significant association between the age group and arches $(\mathrm{p}<0.05)$ (Figure 3$)$.

The limitation of this study is that the number of sample sizes was limited, the socio-economic and educational status was not taken into account, and further studies with a larger sample size will provide a firmer conclusion. There are several factors that contributed to the findings but were not included in the evaluation, such as the cause of tooth loss, the different level of literacy and the socio-economic status of patients. All of these factors needto identify the reason for missing teeth and chronology of loss of teeth.

\section{Acknowledgement and Declarations}

Author 1 (P. Deeksheetha), carried out the study by collecting data and drafted the manuscript after performing the necessary statistical analysis. Author 2 (Dr. Kiran Kumar) aided in conception of the topic, has participated in the study design, statistical analysis and has supervised in preparation of the manuscript. Author 3 (Dr. Nashra Kareem) hascoordinated in developing the manuscript. All the authors have discussed the results among themselves and contributed to the final manuscript. 
Figure 1. Bar chart showing the age distribution of patients reported with Kennedy's Class IV partial edentulous. The X-axis denotes the age group of patients and Y-axis denotes the number of patients reported with Kennedy's Class IV partial edentulous. Among the age groups, patients aged above 60 years old (yellow colour) were most affected by Kennedy's Class IV partial edentulism with a prevalence of $24 \%$. The least age group that was affected by Kennedy's Class IV partial edentulism were patients aged 30 to 39 years old (green colour) with $11.5 \%$ only.

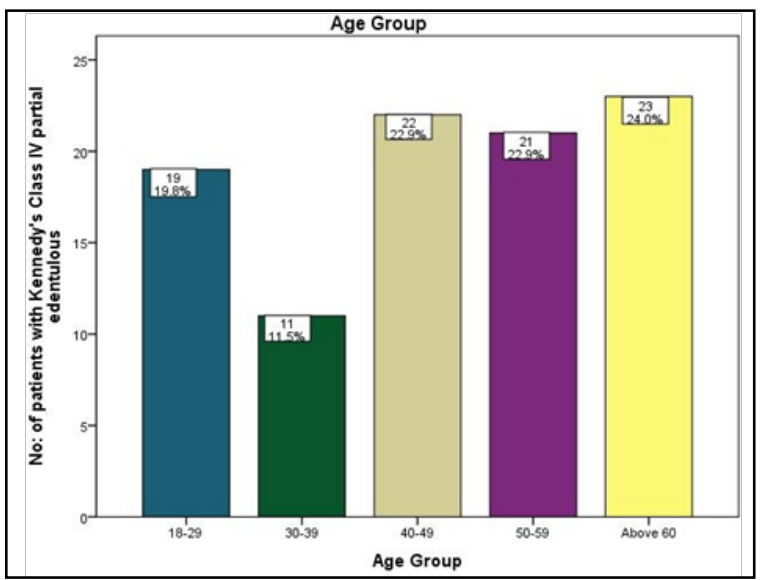

Figure 2. Bar chart depicting the different arch distribution on patients with Kennedy's Class IV partial edentulous. The X-axis denotes the different arches and the Y-axis denotes the number of patients reported with Kennedy's Class IV partial edentulous. The most common arch affected is the mandibular arch (blue colour) (57.3\%).

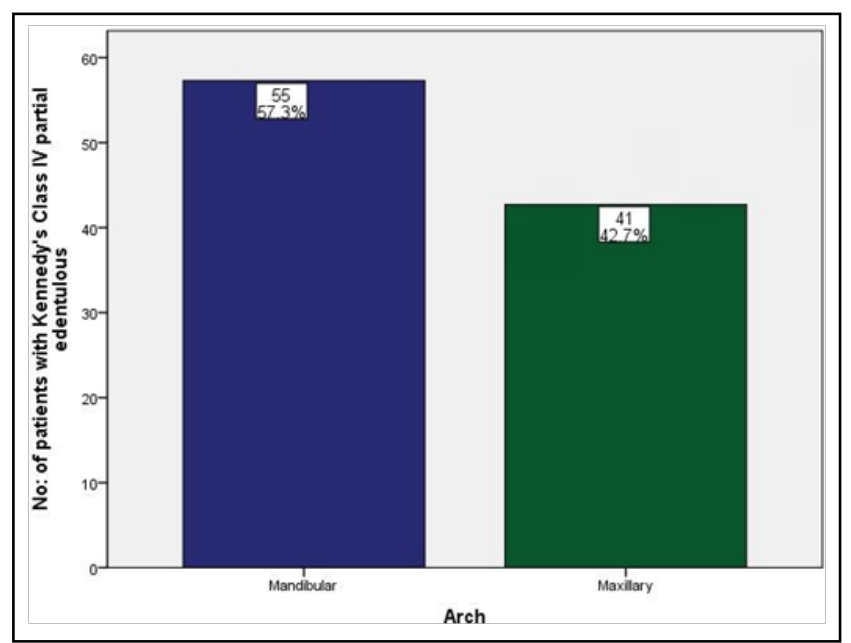

Figure 3. Bar charts represent the association between the age distribution and different arches. The $\mathrm{X}$-axis represents the different age groups of patients with different arches andY-axis represents the number of patients affected by Kennedy's Class IV partial edentulism. We can understand that the most common arch affected with Kennedy's Class IV partial edentulism is the mandibular arch (blue colour) for almost all age groups, except for the age group 18 to 29 years old. In the age group 18 to 29 years old, the maxillary arch (green colour) is most affected by $14.58 \%$. There is a significant difference between the age groups and arches. Pearson's Chi-Square test showing $\mathbf{P}=0.038(\mathbf{P}<0.05)$ indicating statistically significant,

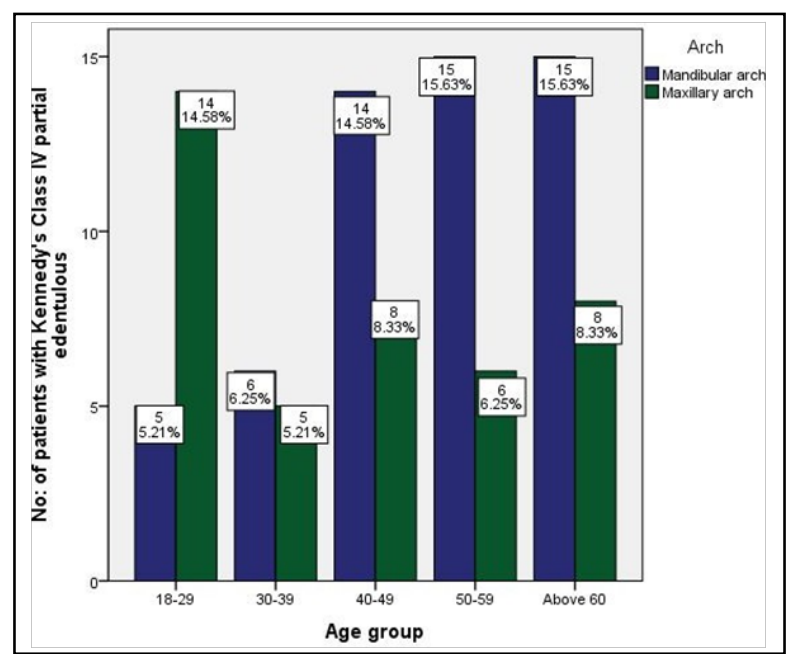




\section{Conclusion}

Within the limits of this study, the study showed that Kennedy's Class IV classification of partial edentulism was more common in the age group above 60 years old (24\%) and most commonly present in the mandibular arch $(57.3 \%)$. There is a significant association between the age group distribution and the different arches for patients with Kennedy's Class IV partial edentulous. Teeth loss tends to have an significant role to play in the loss of esthetics and mastication, and prosthodontic care implemented in order to recover thesefunctions.Further research on the causes for the loss of permanent teeth is needed to coordinate and enforce effective strategies for the prevention and treatment of oraldiseases.

\section{References}

[1]. Bharathi M, Babu KR, Reddy G, Gupta N, Misuriya A, Vinod V. Partial Edentulism based on Kennedy's classifcation: an epidemiological study. J Contemp Dent Pract. 2014 Mar 1;15(2):229-31.Pubmed PMID: 25095849

[2]. Ehikhamenor EE, Oboro HO, Onuora OI, Umanah AU, Chukwumah NM, Aivboraye IA. Types of removable prostheses requested by patients who were presented to the University of Benin Teaching Hospital Dental Clinic. J. Dent. Oral Hyg. 2010 Aug 31;2(2):15-8.

[3]. Muneeb A, Khan BM, Jamil B. Causes and pattern of partial edentulism/exodontia and its association with age and gender: semi rural population, Baqai Dental college, Karachi, Pakistan. Int Dent J Stud Res. 2013 Oct;1:13-8.

[4]. ZAIGHAM AM, Muneer MU. Pattern of partial edentulism and its association with age and gender. Pak Oral Dental J. 2010 Jun 1;30(1).https:// scholar.google.com/scholar?hl=en\&as_sdt=0\%2C5\&q=Pattern+of+partial+ edentulism+and+its+association+with+age+and+gender\&btnG=

[5]. Shah N, Parkash H, Sunderam KR. Edentulousness, denture wear and denture needs of Indian elderly--a community-based study. J Oral Rehabil. 2004 May;31(5):467-76. Pubmed PMID: 15140173.

[6]. Öwall B, Käyser AF, Carlsson GE. Prosthodontics: principles and management strategies. Mosby Inc. 1996. 256.

[7]. Lone MA, Shah SA, Mir S. Pattern of partial edentulism based on Kennedys classification among dental patients in Kashmir: retrospective study. 2019.

[8]. Kida IA, Astrøm AN, Strand GV, Masalu JR. Clinical and socio-behavioral correlates of tooth loss: a study of older adults in Tanzania. BMC Oral Health. 2006 Mar 15;6:5. Pubmed PMID: 16536880.

[9]. Savage KO, Ayanbadejo PO. Pattern of Exodontia treatment need of adults attending the Lagos University Teaching Hospital Dental Clinic. Nig Q J Hosp Med. 2008;15(2):106-9.

[10]. Manimaran P, Kumar CD, Saisadan D, Abirami M, Kumar N, Mani J. Partial Edentulousness in a Rural Population Based on Kennedy's Classification: Epidemiological Study. J Pharm Bioallied Sci. 2017 Nov;9(Suppl 1):S34S36.Pubmed PMID: 29284932.

[11]. Sharma A. Description of Partial Edentulism among Patients Visiting the Prosthodontic Department at a Tertiary Care Center in the Eastern part of Nepal. Acta sci. dent. sci. 2019;3:130-7.

[12]. Peltzer K, Hewlett S, Yawson AE, Moynihan P, Preet R, Wu F, et al. Prevalence of loss of all teeth (edentulism) and associated factors in older adults in China, Ghana, India, Mexico, Russia and South Africa. Int J Environ Res Public Health. 2014 Oct 30;11(11):11308-24.Pubmed PMID: 25361046.

[13]. Rana SB, Acharya B, Bhochhibhoya A, Sharma R, Acharya J, Mainali A. Patterns of partial edentulism based on Kennedy's classification among patients reporting to Nepal Medical College and Teaching Hospital. Kathmandu Univ Med J . 2018;7(4):153-7.

[14]. McGarry TJ, Nimmo A, Skiba JF, Ahlstrom RH, Smith CR, Koumjian JH, et al. Classification system for partial edentulism. J Prosthodont. 2002 Sep;11(3):181-93.

[15]. Curtis DA, Curtis TA, Wagnild GW, Finzen FC. Incidence of various classes of removable partial dentures. J Prosthet Dent. 1992 May;67(5):664-7. Pubmed PMID: 1527752

[16]. Jeyapalan V, Krishnan CS. Partial Edentulism and its Correlation to Age, Gender, Socio-economic Status and Incidence of Various Kennedy's Classes- A Literature Review. J ClinDiagn Res. 2015 Jun;9(6):ZE14-7.Pubmed PMID: 26266237.

[17]. Almakrami FM. Pattern of partial edentulism among Najranian subpopulation and its association with related factors. J Int Med Res. 2018;4(3):86-94.

[18]. Anand PS, Kamath KP, Nair B. Trends in extraction of permanent teeth in private dental practices in Kerala state, India. J Contemp Dent Pract. 2010 May 1;11(3):041-8.Pubmed PMID: 20461323.

[19]. Pallegedara C, Ekanayake L. Tooth loss, the wearing of dentures and associated factors in Sri Lankan older individuals. Gerodontology. 2005 Dec;22(4):193-9.Pubmed PMID: 16329226.

[20]. Jandial S, Gupta R, Sharma S, Mahajan N, Kotwal B, Kharyal S. Incidence of Partial Edentulism Based on Kennedy's Classification in Jammu. Int. j. preventive public health sci. 2017 Mar 30;3(2):38-40.

[21]. AL-Dosari AM, AL-Wazan KA, AL-Garni MS, Abdulmajid. Tooth loss pattern andedentulousness among 1400 Saudi patients. Cairo Dent J.1997;31(13).

[22]. Al Moaleem MM, Somaili DM, Ageeli TA, Namis SM, Mobarki AH, Mohamed MS, et al. Pattern of partial edentulism and its relation to age, gender, causes of teeth loss in Jazan population. American Journal of Health Research. 2016 Aug 26;4(5):121-6.

[23]. Al-Ansari AA. Prevalence, severity, and secular trends of dental caries among various Saudi populations: A literature review. Saudi J Med Med Sci. 2014 Sep 1;2(3):142.

[24]. Vijayalakshmi B, Ganapathy D. Medical management of cellulitis. Research J. Pharm. and Tech.2016;9(11):2067-70.

25]. Jain AR, Nallaswamy D, Ariga P, Ganapathy DM. Determination of correlation of width of maxillary anterior teeth using extraoral and intraoral factors in Indian population: A systematic review. World J Dent. 2018 Jan;9:68-75.

[26]. Subasree S, Murthykumar K. Effect of Aloe Vera in Oral Health-A Review. Research J. Pharm. and Tech. 2016;9(5):609-12.

[27]. Basha FYS, Ganapathy D, Venugopalan S. Oral Hygiene Status among Pregnant Women. Research J. Pharm. and Tech. 2018;11: 3099.

[28]. Pandurangan KK, Veeraiyan DN, Nesappan T. In vitro evaluation of fracture resistance and cyclic fatigue resistance of computer-aided design-on and hand-layered zirconia crowns following cementation on epoxy dies. J. Indian Prosthodont. Soc. 2020 Jan 1;20(1):90.

[29]. Inchara R, Ganapathy D, Kumar PK. Preference of antibiotics in pediatric dentistry. Drug Invent Today. 2019 Jun 15;11:1495-98.

[30]. Reddy BA, Ganapathy D, Kumar PK. Prevalence of toothpaste swallowing habit in children between the age group of 3 and 5 years.

[31]. Anjum AS, Ganapathy D, Kumar K. Knowledge of the awareness of dentists on the management of burn injuries on the face. Drug Invention Today. 2019 Sep $15 ; 11(9)$.

[32]. Ramya G, Pandurangan K, Ganapathy D. Correlation between anterior crowding and bruxism-related parafunctional habits. Drug Invention Today. 2019 Oct 15;12(10)

[33]. Shree Y, Kumar K, Ganapathy D. Awareness of basic life support among dentalstudents.researchgate.net.

[34]. Ashok V, Nallaswamy D, Benazir Begum S, Nesappan T. Lip Bumper Prosthesis for an Acromegaly Patient: A Clinical Report. J Indian Prosthodont Soc. 2014 Dec;14(Suppl 1):279-82.Pubmed PMID: 26199531.

[35]. Venugopalan S, Ariga P, Aggarwal P, Viswanath A. Case Report: Magnetically retained silicone facial prosthesis. Niger. J. Clin. Pract. 2014 Mar 27;17(2):260-4.

[36]. Ganapathy D, Sathyamoorthy A, Ranganathan H, Murthykumar K. Effect of Resin Bonded Luting Agents Influencing Marginal Discrepancy in All Ceramic Complete Veneer Crowns. J ClinDiagn Res. 2016 Dec;10(12):ZC67ZC70.Pubmed PMID: 28209008.

[37]. Selvan SR, Ganapathy D. Efficacy of fifth generation cephalosporins against methicillin-resistant Staphylococcus aureus-A review. Research J. Pharm. and Tech.2016;9(10):1815-8

[38]. Jyothi S, Robin PK, Ganapathy D. Periodontal health status of three different groups wearing temporary partial denture. Research J. Pharm. and Tech. 2017;10(12):4339-42.

[39]. Moaleem MA. Patterns of Partial Edentulism and its Relation to Khat Chewing in Jazan Population - A Survey Study. J ClinDiagn Res. 2017 Mar;11(3):ZC55-ZC59.Pubmed PMID: 28511510.

[40]. Devishree RA, Sangeetha S, Jain AR. Prevalence of partial edentulism according to Kennedy's classification based on age, gender, and arch. Drug Invention Today.2018;10(1):108-10.

[41]. Shubita M. Evaluation of partial edentulism based on Kennedy's classification and its relation with age and gender. Pak Oral Dental J. 2015 Dec $1 ; 35(4)$.

[42]. Saleh MM, Tahir CD, Abdel-Rahman HK. Incidence of partial edentulism and its relation with age and gender.Zanco J Med Sci. 2013;17(2):463-70. 